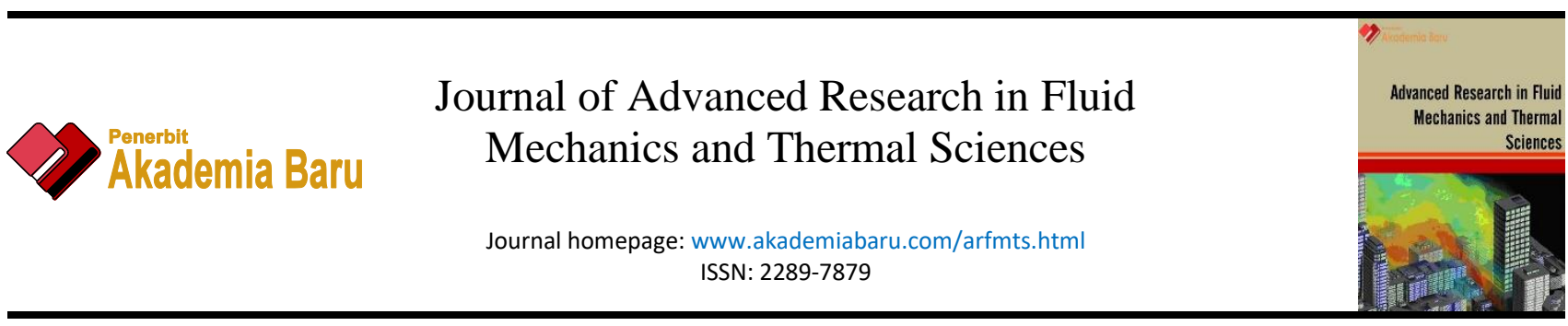

\title{
Effect of Oil Mass Flow Rate on Temperature Profile in Oil Wells
}

\author{
Abdulhafid M. Elfaghi ${ }^{1,}$, Wisam B. Ajaj ${ }^{2}$, Lukmon Owolabi Afolabi ${ }^{1}$ \\ 1 Faculty of Mechanical and Manufacturing Engineering, Universiti Tun Hussein Onn Malaysia (UTHM), 86400 Parit Raja, Batu Pahat Johor, \\ Malaysia \\ 2 Faculty of Natural Resources Engineering Al-Ajailat, University of Zawia, Zawia, Libya
}

\section{ARTICLE INFO}

\section{Article history:}

Received 6 May 2020

Received in revised form 6 June 2020

Accepted 8 June 2020

Available online 10 November 2020

\section{Keywords:}

Mathematical model; Oil well; Temperature profile; Reservoir; Mass flow rate

\section{ABSTRACT}

In several design calculations including the development of programs to optimize production, engineers and scientists require accurate prediction of temperature drop due to flow in oil wells. The purpose of this research is to create mathematical models to predict the effect of oil mass flow rate on temperature distribution in oil wells. A numerical mathematical model is developed to study the parameters affecting the dynamic and static temperature profiles in oil wells in production and shutting operation. The temperature distribution of the oil from the reservoir to the surface and the temperature distribution in the wall tubing of the oil well and casing, cement sheaths, and surrounding formation is studied. The natural flow of oil wells in Alwahat area located 70 Kilometres south of Marada area east of Libya in the Zaggut field called (6Q1-59) is taken as a study case. In production case, different mass flow rates in winter and summer seasons are studied. The temperature profile in the horizontal direction is estimated at different depths. The Results show that the surface temperature of crude oil increases with the rise in mass flow rate.

\section{Introduction}

Crude petroleum is a complex mixture of primarily paraffin, naphthalene, and aromatic hydrocarbons. There are two ways to collect the oil from the earth, the natural flow and the pumping process. The method of pumping is used to extract oil from the reservoir to the earth's surface. This process is used where the pressure difference is not sufficient to allow oil to rise because the proportion of the gas melt in the oil is not sufficient to make it flow naturally, so certain wells have a high proportion of the wax mixed with oil. The design of the pump depends on the well depth and the specified oil. When a fluid flows in a tubing, the properties of the fluid will be affected by the rate

\footnotetext{
* Corresponding author.

E-mail address: abdulhafid@uthm.edu.my
}

https://doi.org/10.37934/arfmts.77.2.2332 
of flow, tubing diameter, tubing roughness, and the properties of the surrounding formation. During extraction of oil, the oil temperature varies as it flows from the reservoir to the surface. The fluid enters into the wellbore at high temperatures near to the reservoir. As the fluid flows into the wellhead, oil temperature decreases as a result of heat transfer to the surrounding earth. During production process, heat is usually conducted throughout tubing, to annulus fluid, casing, cement sheaths, and surrounding formation. Thus, each of these media has individual thermal properties which make prediction of heat transfer more complex. Moreover, opening, shutting, restarting and altering the production schedule are also the regular and daily program of a well-producing operation, each of these operations performed in the temperature profile estimation in the oil wells. In this paper, a numerical model is developed to study the parameters affecting the dynamic and static temperature profiles in the oil well, the prediction of temperature profile estimation in the oil wells. Thus far, this paper, a numerical model is developed to study the parameters affecting the dynamic and static temperature profiles in the oil well. Furthermore, the prediction of temperature profile in production and shutting operation will be studied.

There are two important contributory factors of heat transfer of the fluid, firstly, transfer of energy up inside the well is accomplished by the fluid flow, which it depends on fluid properties. Secondly, radial heat conduction from the well passing through the tubing, annular fluid to the casing, cement sheaths, and throughout surrounding formation.

Thomas [1] suggested an estimated method to assess the temperature profile when the fluid is hot injected. This approximation is important in the case of distinctly thin reservoir beds where the fluid injected goes with high flow. The main factors in process design and production management are mathematical prediction models of temperature distribution across porous media during thermal flood processes [2]. Several models are proposed for the distribution of temperature in specific geothermal and natural reservoirs and for the thermal injection model well-tested $[3,4]$. Lawal and Vesovic [5] developed a one-dimensional heat transfer model to predict the distribution of temperatures for various conditions. Authors used the relation between the temperature-dependent oil density and the viscosity of a bitumen reservoir. As for the relative importance of natural convection, authors have used the magnitude of Nusselt number and concluded that the importance of free convection depends on the properties of rock and fluid including the duration of heating. Lawal [6] modified this model for a steam-flooding operation. The author concluded that a maximum of four zones (i.e., condensation, convection, conduction, and quiescent) may be defined at any moment of the thermal flood.

Ramey [7] developed an approximate solution to the transient heat conduction problem involving the passage of hot fluids through a well bore. It was assumed that the heat transfer in the well bore was stable, and the transfer of heat to earth was unstable radial convection, and often called the effect of thermal resistance in the well bore. The solution allowed the fluid, tubing, and casing temperature estimation as a function of depth and time. Willhite [8] provided a detailed method for calculating the overall heat transfer coefficient $(U)$ for the completion in terms of natural convection, conduction and radiation. This coefficient was found to be critical for estimating the temperature profile in the well. Hasan and Kabir [9] have created a model that incorporates a new Thermal Diffusiveness Equation solution. This approach allows integration of conductive and convective heat transport effect between the well bore and the shape. A sensitivity study has showed that significant differences exist between the predicted wellhead temperature and the surface temperature, and that the fluid temperature gradient has found nonlinear. Their study further has showed that an increase in free gas caused a lowering of wellhead temperature due to the Joule-Thomson (JT) effect. For these situations, when multiphase flow was encountered the expression for fluid temperature developed by Ramey [7] for single-phase flow was not applied. 
Hossain et al., [2] proposed methods that are used to establish design conditions for geothermal wells with high temperatures including in it the geological conditions and types of reservoirs. The primary basis for casing design is the temperature and pressure for a flowing and a shut-in well. Xiongdong et al., [10] put together two theoretical models. The models were based on balance of energy between the formation and fluid that flows through each conduit. Temperature profiles were obtained with the proposed temperature model, and the results were compared with the measured data. Samsuri et al., [11] studied the variation of original oil due to porosity estimation technique. It concluded that original oil in place estimation is significantly influenced by technique used for porosity determination in an interbedded reservoir as compared with a clean sand reservoir. Kutun et al., [12] developed a computational model to study the factors that influence the dynamic and static temperature profiles in geothermal wells. The model was based on equations of mass and energy balance and coupled the reservoir to the well and took into account the heat losses from the well's surroundings. Within the literature the model was tested using various analytical methods. A synthetic method has been developed to define key parameters influencing temperature distribution during both production operations and injection. Temperature behavior along the well was obtained in the application model for a transition from static to dynamic.

\section{Mathematical Model}

The surrounding formation $\left(\mathrm{T}_{\infty}\right)$ as stated in the nomenclature, constitute other temperature variables such as temperature gradient, pressure gradient, surface temperature and depth. The change in temperature over the change in distance ( $d T / d x)$, is known as temperature gradient (TG) and the pressure gradient is the change in pressure over the change in distance, $d P / d x$ [13]. Thus, the surrounding formation $\left(\mathrm{T}_{\infty}\right)$ is computed at specific distance and depth using the following equation.

$\mathrm{T}_{\infty}(\mathrm{z})=\mathrm{TG} *$ Depth $+T_{\operatorname{sur}(\mathrm{z})}$

where the (TG) thermal gradient and expressed as by Çengel [13]

$\mathrm{TG}=\frac{T_{b h}-\mathrm{Tsur}}{\text { Total depth }}$

The following equation is used to calculate the thermal resistance $\left(R_{t h}\right)$ for vertical section of oil well as shown in Figure 1.

$$
\begin{aligned}
& \mathrm{Rth}_{\text {total }}=\mathrm{R}_{1}+\mathrm{R}_{2}+\mathrm{R}_{3}+\mathrm{R}_{4}+\mathrm{R}_{5}+\mathrm{R}_{6} \\
& \mathrm{Rth}_{\text {total }}=\left(\frac{1}{\text { h. }(\pi \cdot \mathrm{d} \cdot \Delta \mathrm{z})}\right)_{1}+\left(\frac{\ln \left(\frac{\mathrm{ro}}{\mathrm{ri}}\right)}{2 \pi \mathrm{k} \Delta \mathrm{z}}\right)_{2}+\left(\frac{\ln \left(\frac{\mathrm{ro}}{\mathrm{ri}}\right)}{2 \pi \mathrm{k} \Delta \mathrm{z}}\right)_{3}+\cdots+\left(\frac{\ln \left(\frac{\mathrm{ro}}{\mathrm{ri}}\right)}{2 \pi \mathrm{k} \Delta \mathrm{z}}\right)_{\mathrm{n}}
\end{aligned}
$$




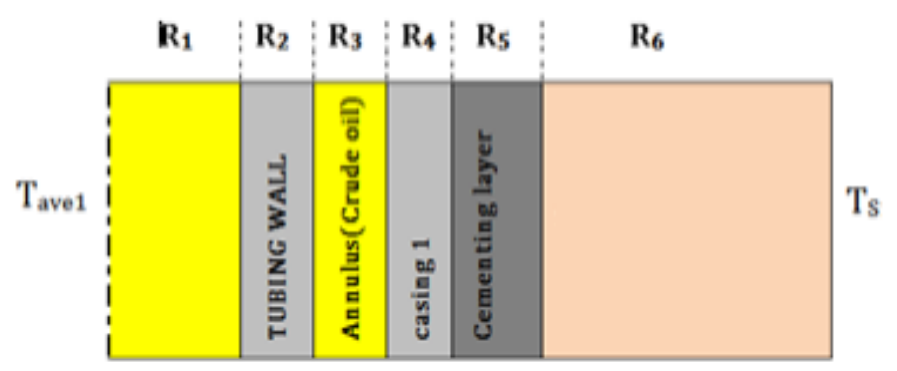

Fig. 1. Thermal resistance in vertical section of oil well

In order to simplify the derivations of the mathematical model, the flow is assumed to be fully developed incompressible single phase. The fluid properties are assumed constant with temperature at a specific distance $(\mathrm{dx})$, more so, increasing or decreasing fluid mass flow rate can affect the temperature distribution significantly, and the heat transfer by conduction in vertical direction (z) is negligible. The conservation of energy equation for the steady flow of a fluid in a tubing by Ennil and Elfaghi [14] as shown in Figure 2 can be expressed as

$\dot{\mathrm{Q}}=\dot{\mathrm{m}} * C p *\left(\mathrm{~T}_{\mathrm{m} . \mathrm{o}}-\mathrm{T}_{\mathrm{m}, \mathrm{i}}\right)$

Applying this equation to the differential control volume (c.v), we obtained

$$
\begin{aligned}
& \mathrm{d} \dot{\mathrm{Q}}=\dot{\mathrm{m}} * \mathrm{Cp} *\left(\left[\mathrm{~T}_{\mathrm{m}}+\mathrm{dT}_{\mathrm{m}}\right]-\mathrm{T}_{\mathrm{m}}\right) \\
& \mathrm{d} \dot{\mathrm{Q}}=\dot{\mathrm{m}} * \mathrm{Cp} * \mathrm{dT}_{\mathrm{m}}
\end{aligned}
$$

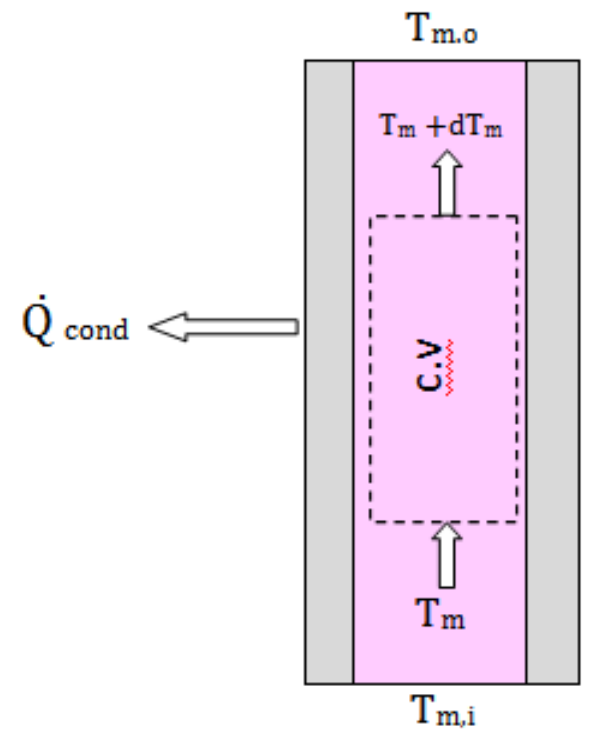

Fig. 2. Control volume for internal flow in oil well

$\mathrm{dQ}_{\text {cond }}^{\cdot}=\frac{\left(\mathrm{T}_{\mathrm{s}}-\mathrm{T}_{\mathrm{m}}\right)}{\mathrm{Rth}_{\text {total }}}$

The equation then takes the form

$\mathrm{dQ}_{\text {cond }}=\mathrm{d} \dot{\mathrm{Q}}$ 
$\frac{\left(\mathrm{T}_{\mathrm{s}}-\mathrm{T}_{\mathrm{m}}\right)}{\mathrm{Rth}_{\text {total }}}=\dot{\mathrm{m}} * \mathrm{Cp} * \mathrm{dT}_{\mathrm{m}}$

The total thermal resistance $\mathrm{Rth}_{\text {total }}$ is calculated from the following equation

$\operatorname{Rth}_{\text {total }}=\left(\frac{1}{\mathrm{~h} \cdot(\pi \cdot \mathrm{d} \cdot \Delta \mathrm{z})}\right)_{1}+\left(\frac{\ln \left(\frac{\mathrm{ro}}{\mathrm{ri}}\right)}{2 \pi \mathrm{k} \Delta \mathrm{z}}\right)_{2}+\left(\frac{\ln \left(\frac{\mathrm{ro}}{\mathrm{ri}}\right)}{2 \pi \mathrm{k} \Delta \mathrm{z}}\right)_{3}+\cdots+\left(\frac{\ln \left(\frac{\mathrm{ro}}{\mathrm{ri}}\right)}{2 \pi \mathrm{k} \Delta \mathrm{z}}\right)_{\mathrm{n}}$

$\operatorname{Rth}_{\text {total }}=\frac{1}{\Delta \mathrm{z}}\left(\frac{1}{\mathrm{~h} \cdot(\pi \cdot \mathrm{d})}\right)_{1}+\left(\frac{\ln \left(\frac{\mathrm{ro}}{\mathrm{ri}}\right)}{2 \pi \mathrm{k}}\right)_{2}+\left(\frac{\ln \left(\frac{\mathrm{ro}}{\mathrm{ri}}\right)}{2 \pi \mathrm{k}}\right)_{3}+\cdots+\left(\frac{\ln \left(\frac{\mathrm{ro}}{\mathrm{ri}}\right)}{2 \pi \mathrm{k}}\right)_{\mathrm{n}}$

let $\mathrm{Ri}=\left(\frac{1}{\mathrm{~h} \cdot(\pi \cdot \mathrm{d})}\right)_{1}+\left(\frac{\ln \left(\frac{\mathrm{ro}}{\mathrm{ri}}\right)}{2 \pi \mathrm{k}}\right)_{2}+\left(\frac{\ln \left(\frac{\mathrm{ro}}{\mathrm{ri}}\right)}{2 \pi \mathrm{k}}\right)_{3}+\cdots+\left(\frac{\ln \left(\frac{\mathrm{ro}}{\mathrm{ri}}\right)}{2 \pi \mathrm{k}}\right)_{\mathrm{n}}$

then $\mathrm{Rth}_{\text {total }}=\frac{\mathrm{R}_{\mathrm{i}}}{\Delta \mathrm{z}}$

$\dot{\mathrm{m}} * \mathrm{Cp} * \mathrm{dT}_{\mathrm{m}}=\frac{\left(\mathrm{T}_{\mathrm{s}}-\mathrm{T}_{\mathrm{m}}\right)}{\mathrm{R}_{\mathrm{i}}} \Delta \mathrm{z}$

$\frac{\mathrm{dTm}}{\mathrm{dz}}=\frac{\left(\mathrm{T}_{\mathrm{s}}-\mathrm{T}_{\mathrm{m}}\right)}{\dot{\mathrm{m}} * \mathrm{Cp} * \mathrm{R}_{\mathrm{i}}}$

let $\mathrm{F}_{\mathrm{i}}=\frac{1}{\dot{\mathrm{m}} * \mathrm{Cp} * \mathrm{Ri}}$

where $\mathrm{F}_{\mathrm{i}}$ is constant in the same part but it varied from part to another.

$\frac{\mathrm{dT}_{\mathrm{m}}}{\mathrm{dz}}=\mathrm{F}_{\mathrm{i}}\left(\mathrm{T}_{\mathrm{s}}-\mathrm{T}_{\mathrm{m}}\right)$

$\frac{\mathrm{dT}_{\mathrm{m}}}{\mathrm{dz}}=\mathrm{F}_{\mathrm{i}} \mathrm{T}_{\mathrm{s}}-\mathrm{F}_{\mathrm{i}} \mathrm{T}_{\mathrm{m}}$

$\frac{d T_{m}}{d z}+F_{i} T_{m}=F_{i} T_{s}$

Eq. (20) is a non-homogeneous linear ordinary differential equation (first order ODEs) which is in the form of the following Bernoulli differential equation [15].

$\bar{y}+P(z) y=r(z)$

$y(z)=e^{-N} \int e^{N} \cdot r(z) d z+c e^{-N}$

where $(\mathrm{N})=\int \mathrm{P}(\mathrm{z}) \mathrm{dz}$

Let $P=F, \quad r(z)=F$.Ts, and $T s=b z+a$

The general solution for first - order ODE Eq. (22) is given by the following equation

$\mathrm{T}_{m}=\mathrm{bz}-\frac{\mathrm{b}}{\mathrm{F}}+\mathrm{a}+\mathrm{c} \cdot \mathrm{e}^{-\mathrm{Fz}}$ 
Eq. (23) is used in all parts from the bottom to the top to compute the mean temperature of the oil for every point at any part by using the thermal resistance. After the medium temperatures of the crude oil and the surrounding formation are computed for different depths, the rate of heat transfer is computed from the oil to the layers through the tubing wall and the casing. Then, the temperature distribution in every layer at the same depths are obtained.

$\dot{\mathrm{Q}}=\frac{\mathrm{T}_{\mathrm{ave}}-\mathrm{T}_{\mathrm{S}}}{\mathrm{Rth}_{\mathrm{Tot}}}$

$\dot{\mathrm{Q}}_{\mathrm{i}}=\frac{\mathrm{T}_{(\mathrm{i})}-\mathrm{T}_{(\mathrm{i}+1)}}{\mathrm{R}_{\mathrm{i}}}=\dot{\mathrm{Q}}$

Where $R_{i}$ is the thermal resistance of layer (i)

$\mathrm{T}_{(\mathrm{i}+1)}=\mathrm{T}_{(\mathrm{i})}-\dot{\mathrm{Q}} * \mathrm{R}_{\mathrm{i}}$

This equation computes the temperature distribution in the layers at every layer.

\section{Case Study}

The temperature distribution of the oil from the reservoir to the surface and the temperature distribution in the tubing wall and the surrounding layers of the oil well is taken into account in this research. To calculate the temperature distribution in the wellbore at different depths, the wellbore is divided into four main parts, and then every main part divided to different sections based on the oil well surrounding formation which is shown in the Figure 3. There are four casing; the casings begin around the production tubing from the surface to the different depths, the depths of each casing are determined by the geological conditions, and safety requirements, and there are cement sheaths between each casing. All the casing and the production tube are designed from carbon steel. Figure 4 shows the wellbore schematic and dimensions of the casing and tubing.

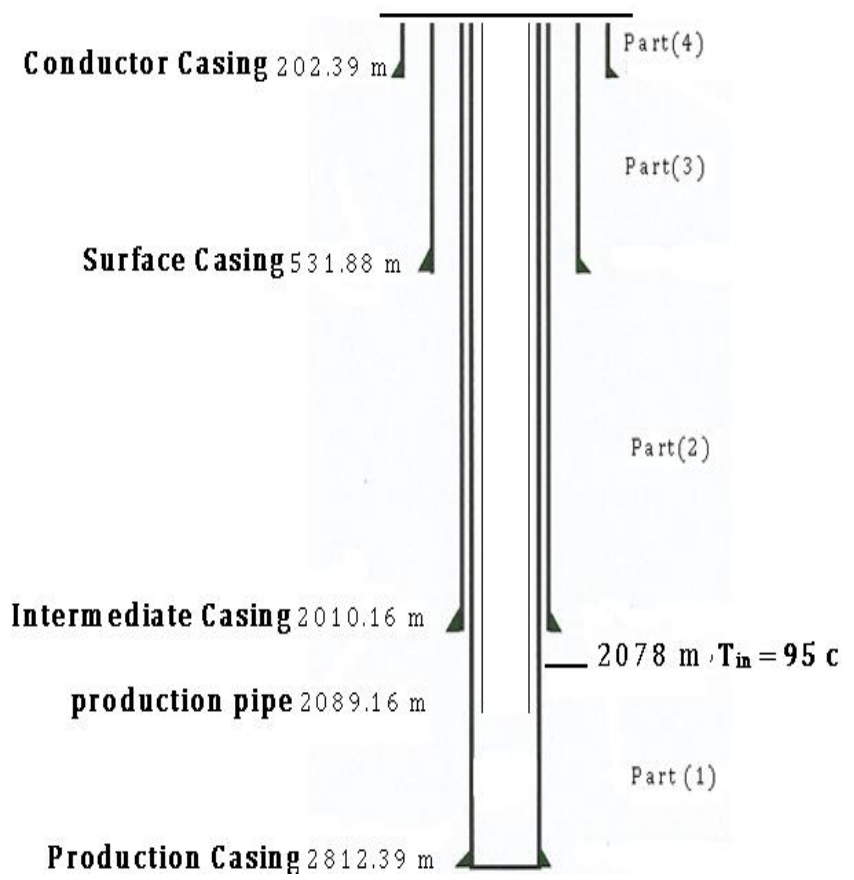

Fig. 3. Schematic well bore diagram 


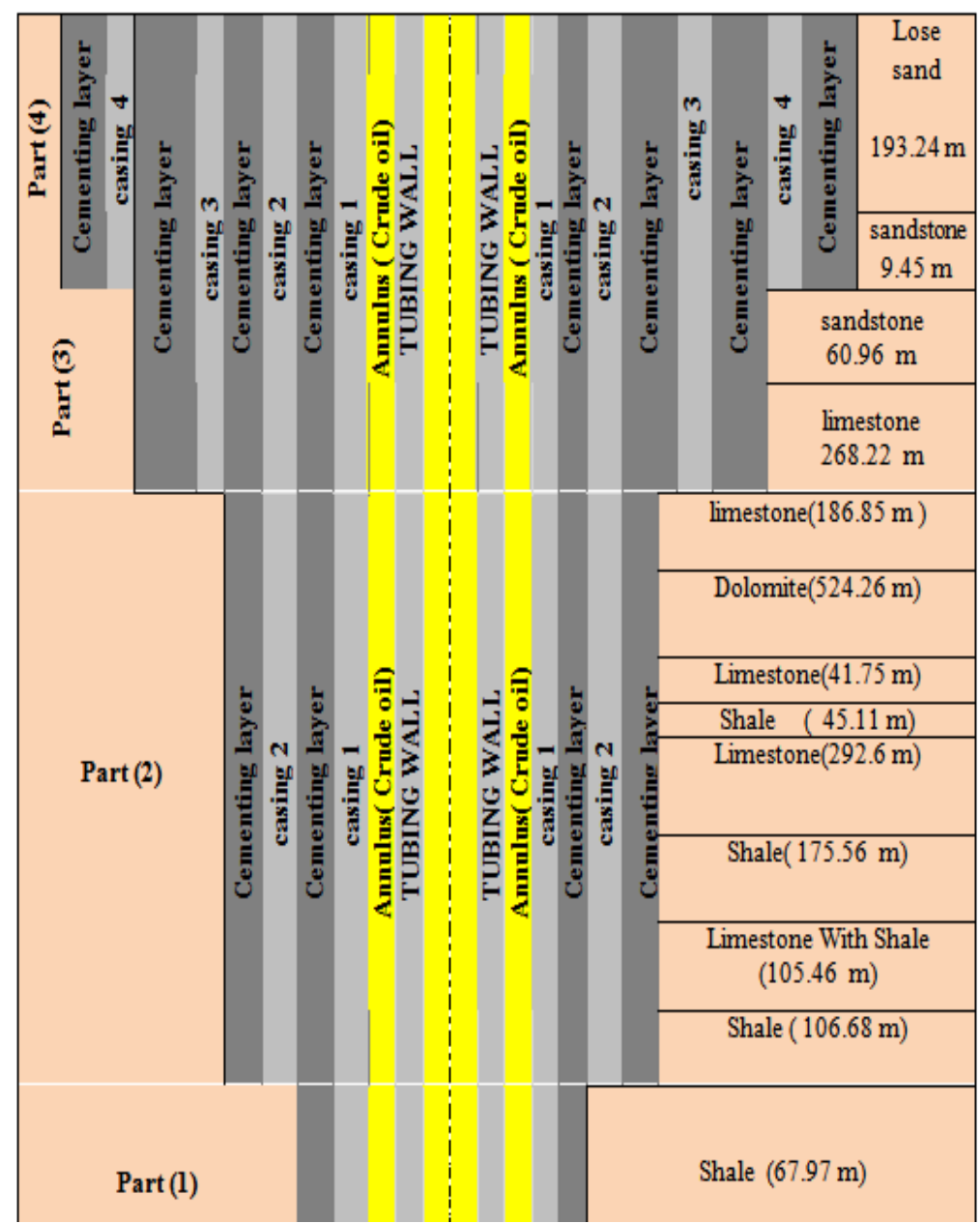

Fig. 4. Vertical section of the oil well and surrounding formation

\section{Results and Discussions}

Figure 5 shows the temperature distributions of surrounding formation at winter and summer seasons. The formation temperature is different based on the surface temperature. The temperature difference between crude oil and the surrounding formation in the winter season is higher than the difference between them in the summer season, because there is a difference in the surface temperature of the earth in summer and winter seasons. The formation temperature effects the temperature profile of the crude oil. The temperature profile for same oil well changed with the change of the season.

Figure 6 shows the temperature distribution at different mass flow rates in winter season. The figure illustrates that with increasing of mass flow rate, the crude oil temperature at the surface is increased. Temperature profile at the depth $1000 \mathrm{~m}$ with difference mass flow rates in summer season is taken as an example. Figure 7 shows temperature distribution from the center of the well pipe to the surrounding layers at two mass flow rates at summer season. The temperature of oil is high and then it drops outside the pipe and remains almost constant through other layers. 


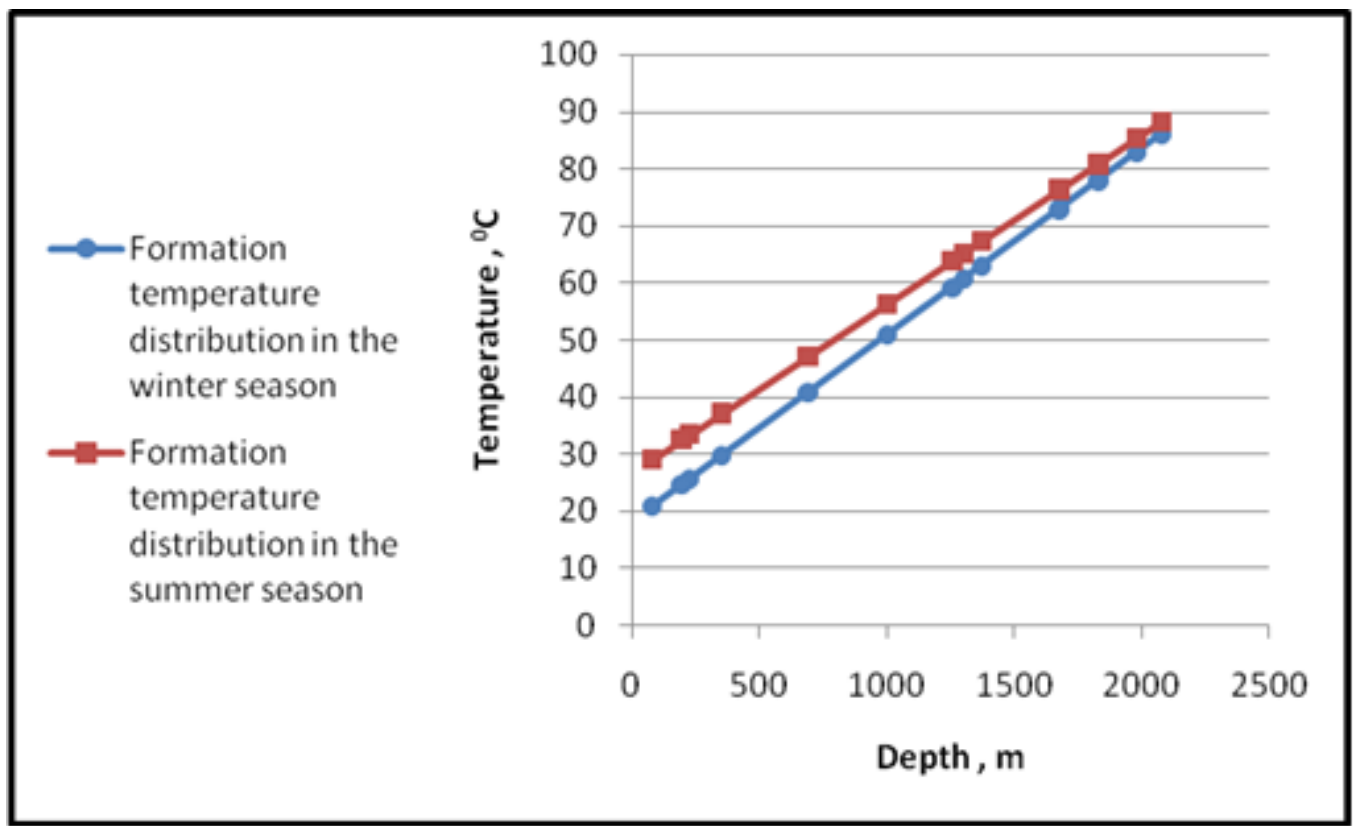

Fig. 5. Formation temperature distribution in different seasons

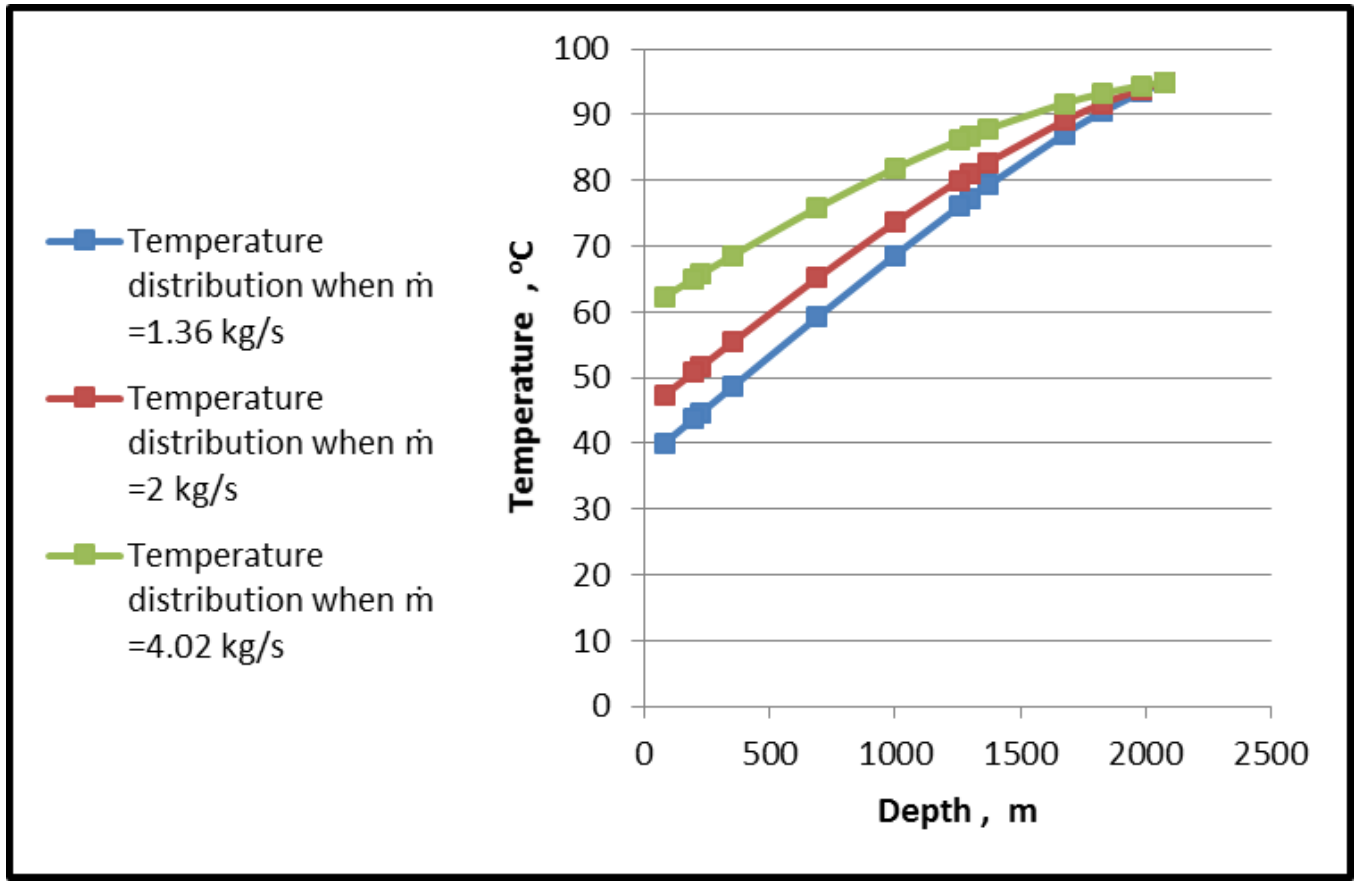

Fig. 6. Temperature distribution for different mass flow rates 


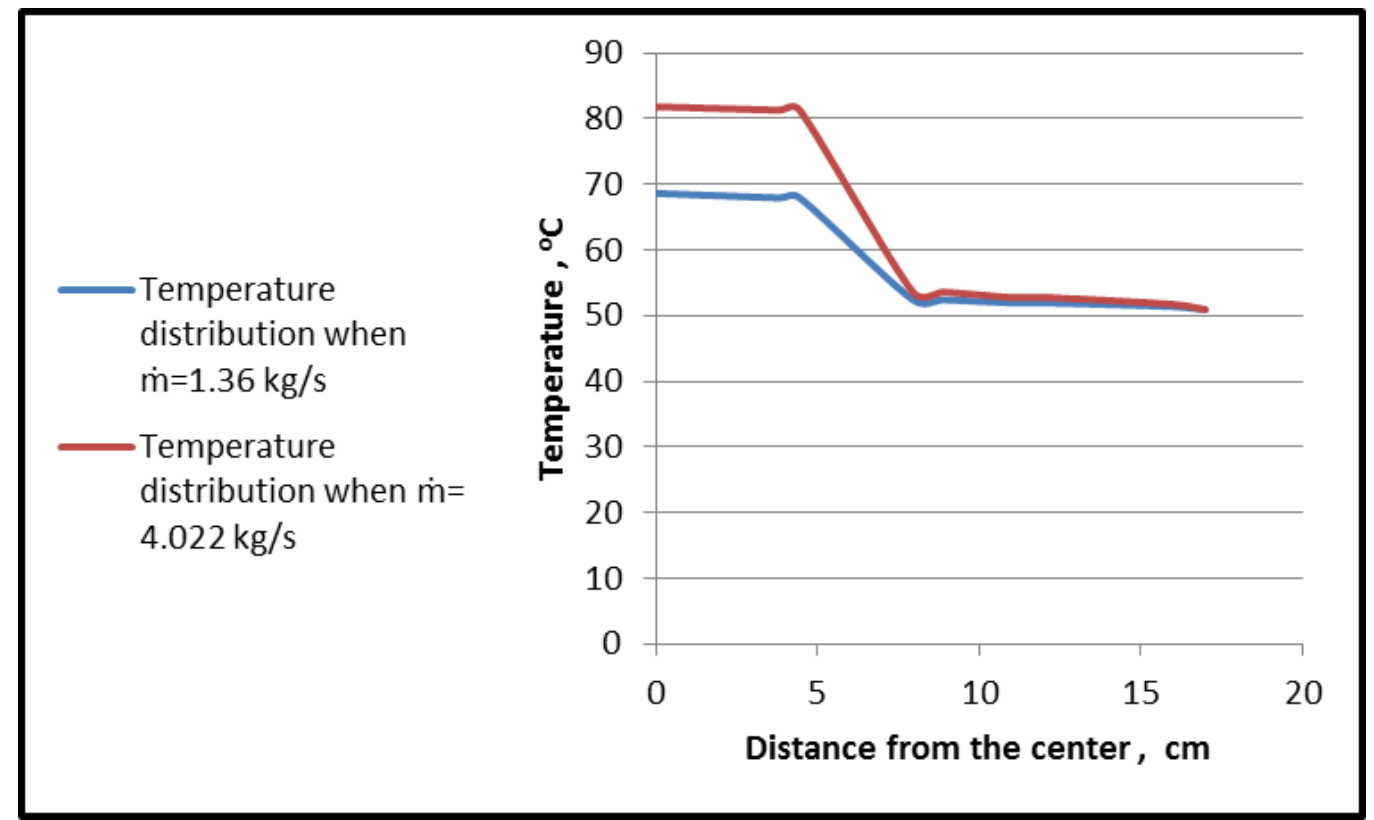

Fig. 7. Temperature profile at depth $1000 \mathrm{~m}$ in summer season for difference mass flow rate

\section{Conclusions}

From the analytical simulation carried out and the data analysis and results, following inference are drawn.

i. The developed mathematical model is able to solve the effect of oil mass flow rate on temperature distribution at production case in oil wells, as well as the temperature distributions along the tubing from the reservoir to the surface.

ii. The created model includes the total thermal resistance and modes of convection heat transferring mechanism were accounted.

iii. The Results show that with increasing of mass flow rate, the crude oil temperature at the surface is increased.

\section{References}

[1] Thomas, G. W. "Approximate methods for calculating the temperature distribution during hot fluid injection." Society of Petroleum Engineers 6, no. 4 (1967): 123-129. https://doi.org/10.2118/67-04-02

[2] Hossain, M. Enamul, Sidqi A. Abu-Khamsin, and Abdul-Aziz Al-Helali. "A mathematical model for thermal flooding with equal rock and fluid temperatures." Journal of Porous Media 18, no. 7 (2015): 731-744. https://doi.org/10.1615/JPorMedia.v18.i7.70

[3] Kocabas, I., and R. N. Horne. "A new method of forecasting the thermal breakthrough time during reinjection in geothermal reservoirs." In Proceedings, 15th Workshop on Geothermal Reservoir Engineering, 1990.

[4] Jahanbani Ghahfarokhi, Ashkan, Tom Aage Jelmert, Jon Kleppe, Mohammad Ashrafi, Yaser Souraki, and Ole Torsaeter. "Investigation of the applicability of thermal well test analysis in steam injection wells for Athabasca heavy oil." In SPE Europec/EAGE Annual Conference. Society of Petroleum Engineers, 2012. https://doi.org/10.2118/154182-MS

[5] Lawal, Kazeem Akintayo, and Velisa Vesovic. "Analytic investigation of convection during conduction heating of a heavy-oil reservoir." In SPE Annual Technical Conference and Exhibition. Society of Petroleum Engineers, 2009. https://doi.org/10.2118/124072-MS

[6] Lawal, Kazeem A. "Zoning Steam-Heated Reservoirs by Heat-Transfer Mechanisms." In SPE Nigeria Annual International Conference and Exhibition. Society of Petroleum Engineers, 2016. https://doi.org/10.2118/184307$\underline{\mathrm{MS}}$

[7] Ramey Jr, Henry J. "Wellbore heat transmission." Journal of petroleum Technology 14, no. 04 (1962): 427-435. https://doi.org/10.2118/96-PA 
[8] Willhite, G. Paul. "Over-all heat transfer coefficients in steam and hot water injection wells." Journal of Petroleum Technology 19, no. 05 (1967): 607-615. https://doi.org/10.2118/1449-PA

[9] Hasan, A. R., and C. S. Kabir. "Heat transfer during two-phase flow in wellbores: Part II-Wellbore." In SPE Annual Technical Conference and Exhibition, pp. 695-708. 1991. https://doi.org/10.2118/22866-MS

[10] Xiongdong, Wu, Zhu Ming, and Han Guoqing. "Wellbore temperature profile prediction in ultra-heavy oil production assisted by light oil in ultra-deep wells." Advances in Information Sciences \& Service Sciences 4, no. 8 (2012): 149-157. https://doi.org/10.4156/aiss.vol4.issue10.18

[11] Samsuri, Ariffin, Zainal Zakaria, Issham Ismail, and M. N. Krishnamurthy. "Estimated original oil in place variation due to porosity determination technique." Journal of Advanced Research in Fluid Mechanics and Thermal Sciences 35, no. 1 (2017): 1-10.

[12] Kutun, Kagan, Omer Inanc Tureyen, and Abdurrahman Satman. "Revisiting the static and dynamic temperature profiles in geothermal wells." In Proceedings, World Geothermal Congress, pp. 19-25. 2015.

[13] Çengel, Yunus A., Robert H. Turner, John M. Cimbala, and Mehmet Kanoglu. Fundamentals of thermal-fluid sciences. Ed. 3. New York: McGraw-Hill, 2001. https://doi.org/10.1115/1.1421126

[14] Ennil, Ali Bahr, and A. M. Elfaghi. "Numerical Simulation of Film Cooling Over Flat Plate." ARPN Journal of Engineering and Applied Sciences 10, no. 6 (2015): 2518-2522.

[15] Kreyszig, Erwin. Advanced Engineering Mathematics (9th ed.). John Wiley \& Sons, 2006. 